\title{
Postoperative Apnea Induced by Fentanyl and Other Multiple Respiratory-Modulating
} Factors

\author{
Chie Matsuda*, Jiro Sato \\ Department of Anesthesiology, Tokyo Women's Medical University, Yachiyo, Japan \\ Email: ${ }^{*}$ chie7020@yahoo.co.jp, sato.jiro@nifty.com
}

Received 1 June 2014; revised 3 July 2014; accepted 26 July 2014

Copyright (C) 2014 by authors and Scientific Research Publishing Inc.

This work is licensed under the Creative Commons Attribution International License (CC BY). http://creativecommons.org/licenses/by/4.0/

(c) (i) Open Access

\begin{abstract}
Purpose: Opioids are concerned as a major cause of postoperative respiratory depression. In the immediate postoperative period, however, other factors can produce instability of breathing such as pain, agitation, and residual effects of anesthetics. Such factors might be overlooked masked by the fear for opioid-induced respiratory depression. We report a case who presented apnea immediately after emergence from anesthesia that we considered was produced by an interaction among such factors accompanied with fentanyl-induced respiratory depression. Clinical Features: A 31-year-old woman underwent ovarian cystectomy under general anesthesia with continuous infusions of propofol and remifentanil, and bolus doses of fentanyl. Transversus abdominis plane blocks with ropivacaine were given upon completion of surgery. She complained of severe wound pain and was agitated at the emergence from anesthesia. Fentanyl $50 \mu \mathrm{g}$ was administered intravenously. In several minutes, she developed apnea, unconsciousness, and difficulty of mechanical ventilation via a face mask. The estimated effect site concentration at the onset of the episode ( 2.9 $\left.\mathrm{ng} \cdot \mathrm{ml}^{-1}\right)$ was approximately the same $\left(3.0 \mathrm{ng} \cdot \mathrm{ml}^{-1}\right)$ as after $30 \mathrm{~min}$ when she regained consciousness and spontaneous breathing. It indicated that not only direct inhibition of the respiratory center by fentanyl but also other stimulatory and inhibitory factors contributed to respiratory arrest. Conclusion: In the immediate postoperative period, transient factors, such as pain, mental instability and anesthetic residues, which are indirectly-related with breathing, can interact each other and with opioids. The interaction would induce apnea through mechanisms combined among direct inhibition of the respiratory center, and modulation of chemical and cortical controls of breathing.
\end{abstract}

\section{Keywords}

Postoperative Apnea, Opioids, Pain, Chemical and Cortical Controls of Breathing

${ }^{*}$ Corresponding author. 


\section{Introduction}

Opioids are feared as inducing postoperative respiratory depression [1] [2]. However, breathing is generated in the brain stem respiratory center, and modulated through largely a combination of chemical, reflex, and cortical control mechanisms. We present here a case agonized by respiratory arrest occurring at the immediate postoperative period. The apnea was considered produced not solely due to opioids but by a multitude of factors, either inhibitory or stimulatory to breathing, interrelating with one another. The factors include chemical and cortical controls of breathing, pain, and respiratory mechanics as well as inhibition of the respiratory center by fentanyl. This report emphasizes the importance of comprehensive knowledge of the respiratory effect of opioids, and other factors that can affect chemical and cortical controls of breathing.

Written consent for publication of this case was obtained from the patient. The Institutional Review Board of Tokyo Women's Medical University declared the study exempt from approval.

\section{Case Report}

A 31-year-old woman $(163 \mathrm{~cm}, 54 \mathrm{~kg})$ was scheduled for resection of an ovarian cyst. Preoperative routine examinations revealed no abnormalities. She had no history of allergies. At the preoperative visit, she expressed extraneous concerns about postoperative pain seemingly beyond the extent of normal preoperative anxiety. General anesthesia combined with epidural anesthesia was planned. We, however, were forced to halt epidural catheterization due to her intolerance to the procedure despite a prior intravenous (i.v.) administration of $100 \mu \mathrm{g}$ fentanyl and an affable conduct. General anesthesia was induced with remifentanil $0.5 \mu \mathrm{g} \cdot \mathrm{kg}^{-1} \cdot \mathrm{min}^{-1}$ and a target-controlled infusion (TCI) of propofol targeted at the effect-site concentration of $4.0 \mu \mathrm{g} \cdot \mathrm{ml}^{-1}$. Tracheal intubation was facilitated by an i.v. rocuronium $40 \mathrm{mg}$. Anesthesia was maintained with propofol TCI at $1.5-2.5$ $\mu \mathrm{g} \cdot \mathrm{ml}^{-1}$ and a continuous i.v. remifentanil $0.1-0.6 \mu \mathrm{g} \cdot \mathrm{kg}^{-1} \cdot \mathrm{min}^{-1}$, supplemented with bolus doses of fentanyl 50 $100 \mu \mathrm{g}$ each (a total of $450 \mu \mathrm{g}$ ). One minute before the end of surgery, an i.v. patient-controlled analgesia with fentanyl (IV-PCA, a background rate of $0.52 \mu \mathrm{g} \cdot \mathrm{kg}^{-1} \cdot \mathrm{h}^{-1}$ with rescue doses of $28 \mu \mathrm{g}$ and 20 min lockout intervals) was initiated. The operation time was $62 \mathrm{~min}$. On the completion of surgery, ultrasound-guided transversus abdominis plane (TAP) blocks both sides were administered with ropivacaine $80 \mathrm{mg}$ on each side. Fifteen minutes later, sugammadex $200 \mathrm{mg}$ was administered upon arousal. Immediately following extubation, she not only exhibited agitation and hyperventilation accompanied with occasional breath-holdings, but also complained of severe pain rubbing her lower abdomen. Fentanyl $50 \mu \mathrm{g}$ was administered, but seemed ineffective. Within a few minutes she suddenly lost consciousness and became apneic. Mechanical ventilation through a face mask with oxygen (8 L·min ${ }^{-1}$ ) was initiated instantaneously. It, however, was inefficient, and oxygen saturation dropped to approximately $60 \%$. Supplementation of sevoflurane 5\% into the inspired gas gradually ameliorated ventilation difficulty, restoring oxygen saturation to $98 \%$. She regained consciousness and spontaneous breathing 30 min later and complained again of moderate wound pain. Additional four aliquot doses of i.v. fentanyl 25 $\mu \mathrm{g}$ each in $20 \mathrm{~min}$, and a rectal acetaminophen $300 \mathrm{mg}$ did not alleviate pain, and therefore we performed a wound infiltration of ropivacaine $120 \mathrm{mg}$.

In the ward, IV-PCA was continued for $48 \mathrm{~h}$ postoperatively. The patient self-administered rescue doses 12

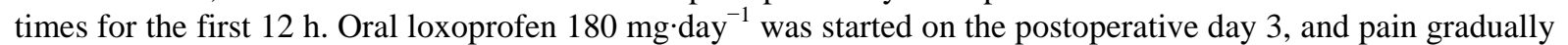
subsided. Otherwise, she experienced an uneventful postoperative course and discharged from the hospital on the postoperative day 7.

The concentrations of propofol, remifentanil, and fentanyl in the effect sites and in plasma were estimated using pharmacokinetic and pharmacodynamic models developed by Mash for propofol, by Minto for remifentanil, and by Shafer for fentanyl, respectively. (TIVA Trainer ${ }^{\mathbb{C}}$ version 9, Eurosiva, The Netherlands). The results were presented in Figure 1.

\section{Discussion}

An amount of fentanyl $50 \mu \mathrm{g}$, administered at the emergence from anesthesia was perhaps insufficient as a sole cause of apnea induced by depressing the activity of the respiratory center. Indeed, the estimated effect site concentration of fentanyl at the onset of apnea $\left(2.9 \mathrm{ng} \cdot \mathrm{ml}^{-1}\right)$ was approximately the same as that at regaining spontaneous breathing and consciousness (3.0 ng. $\mathrm{ml}^{-1}$ ) (Figure 1). Therefore, it is likely that a multitude of factors, either concerting or conflicting, intertwined complexly one another, producing respiratory arrest as schematized 

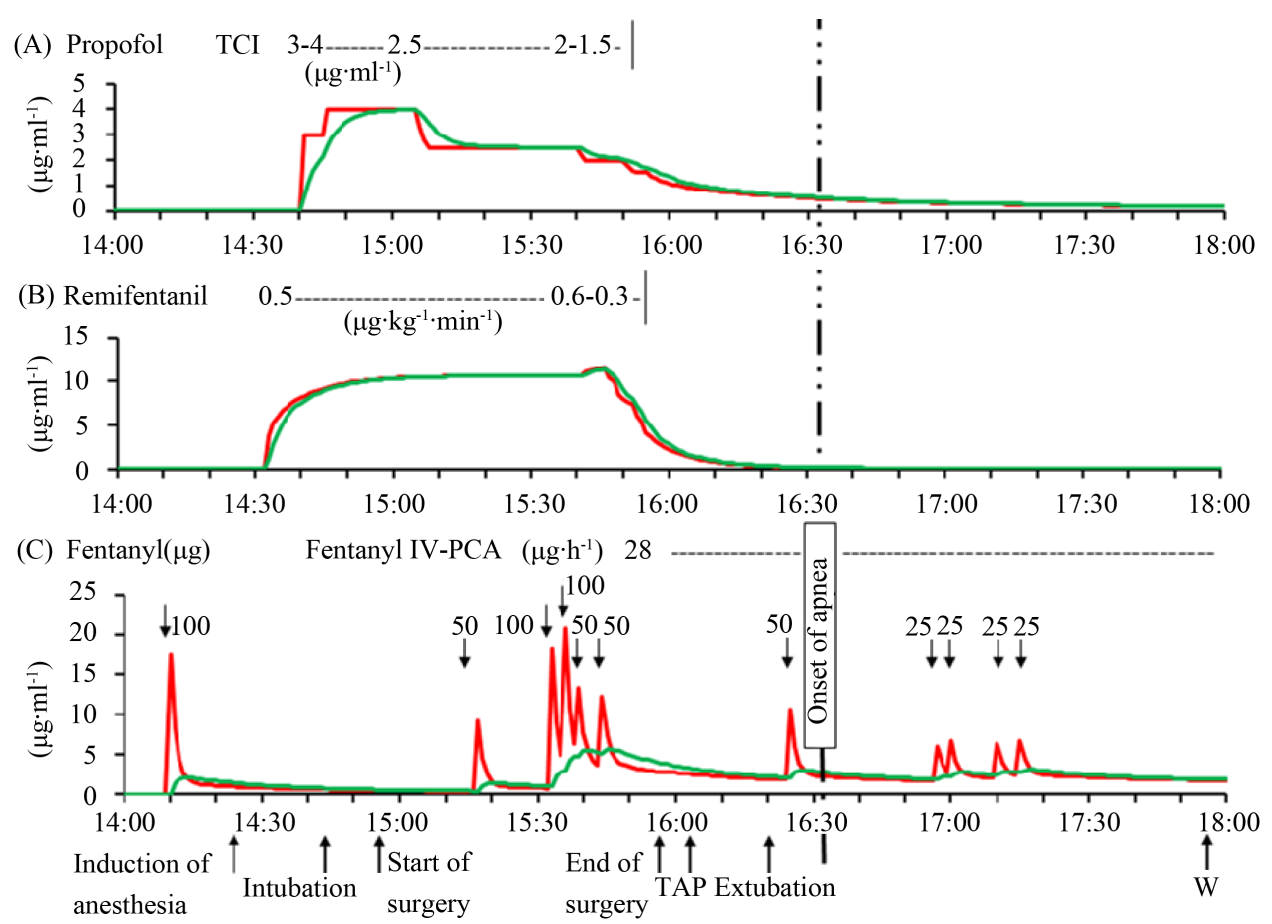

Figure 1. Estimated concentrations at the effect site (green lines) and in plasma (red lines) of propofol (A), remifentanil (B), and fentanyl (C) during the clinical course. They were estimated using the Marsh model for propofol, the Minto model for remifentanil, and the Shafer pharmacokinetic and pharmacodynamic model for fentanyl. (TIVA Trainer ${ }^{\odot}$ version 9, Eurosiva, The Netherlands). TAP: transversus abdominis plane blocks; WI: wound infiltration of ropivacaine.

in Figure 2. Plausible mechanisms responsible for the apnea that we consider are: 1) an excitation of the respiratory center by pain and instabilities in mentality and emotions, and contrarily an inhibition of the respiratory center by fentanyl; 2) a reduction of pain-augmented respiratory drive by fentanyl and TAP blocks; 3) hyperventilation by emotional distress and pain leading to hypocapnia, and a blunted ventilatory response to carbon dioxide by fentanyl; 4) respiratory depression due to residual narcosis by propofol; and 5) glottic closure induced by fentanyl. Considering the marginal concentrations estimated of remifentanil both in the effect site and in plasma, the effect of remifentanil would be negligible.

At the emergence from anesthesia, the patient was agitated and complained of severe wound pain. Emotional upset stimulates the respiratory center [3]. Pain works itself as a respiratory stimulant [4] by acting both on the respiratory center [5] and on the central chemoreceptors [6]. Both emotional disruption and pain aggravate each other [7], further stimulating breathing and thus leading to a vicious spiral of hyperventilation. On the other hand, respiratory inhibitions, though each small, by residues of propofol and fentanyl administered during anesthesia [8] might still remain at the period. It is, therefore, likely that the patient's breathing was maintained on a delicate balance between stimulatory and inhibitory effects of these factors.

It is possible that two analgesic regimens, TAP blocks and i.v. $50 \mu \mathrm{g}$ fentanyl, at the emergence from anesthesia disrupted the balance, resulting in apnea. The TAP blocks reduced wound pain, possibly diminishing pain-augmented respiratory drive. Indeed, several studies and case reports indicated an important role of pain in the maintenance of breathing. Combes et al. [9] demonstrated in patients treated postoperative pain by i.v. morphine that complete pain resolution by supplemental peripheral nerve block worsened respiratory depression. In patients medicated large doses of slow-release opioids without successful relief of cancer or chronic pain, spinal cordotomy or epidural analgesia produced life-threatening respiratory arrest [10]-[12].These studies suggest that unrelieved pain offsets opioid-induced respiratory depression, thus helping barely keep respiratory drive. It was indicated that complete resolution of pain attained by spinal cordotomy or epidural analgesia diminished painstimulated respiratory drive.

Furthermore, the $50 \mu \mathrm{g}$ fentanyl administered immediately after the emergence from anesthesia decreased pain intensity, awareness, and emotional instability, that would reduce in an interactive manner those respiratory 
stimulating effects [5] [6] [8] [13] [14]. In addition to a direct inhibition of the respiratory center, chemoreceptor depression by the $50 \mu \mathrm{g}$ fentanyl would be enhanced under the hyperventilation-induced hypocapnia, more likely inducing apnea (Figure 3) [15]. Besides, we experienced a difficulty in mechanical ventilation via a face mask at the onset of apnea. It indicated that opioid-induced laryngeal closure might take some role in the respiratory arrest [16]-[19].

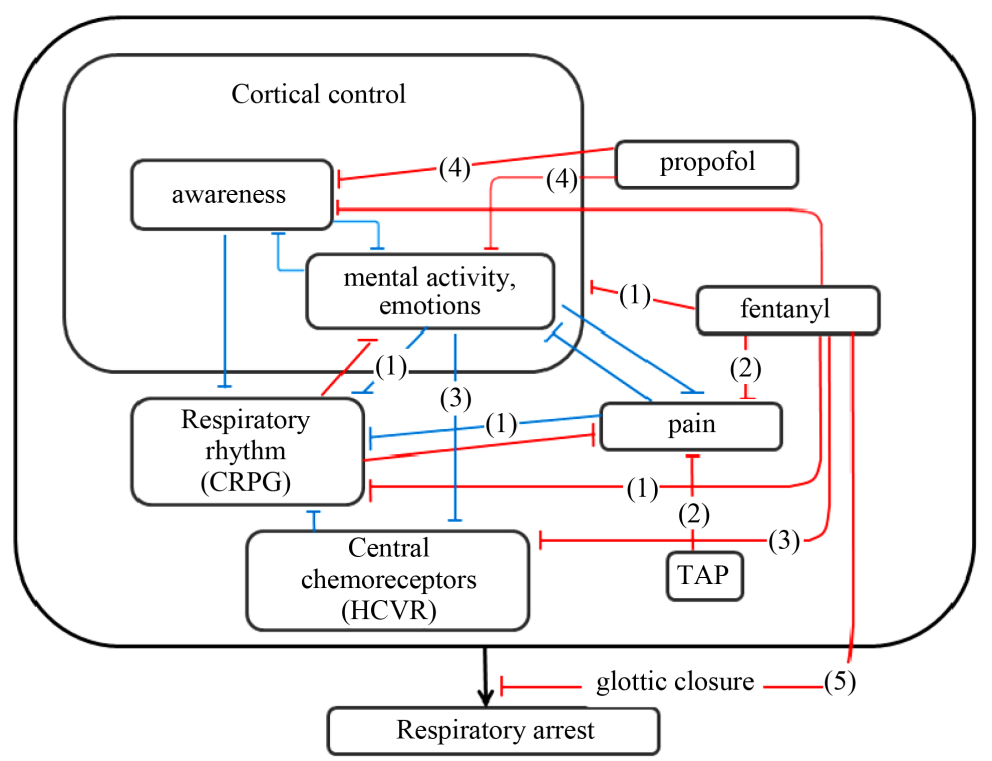

Figure 2. Plausible model interpreting respiratory arrest induced in the patient. CRPG, HCVR, and TAP denote the central respiratory pattern generator (the respiratory center), hypercapnic ventilatory response, and transversus abdominis plain blocks, respectively. Bracketed numbers are either stimulatory or inhibitory effects listed in the text. See the text in detail. Blue and red lines indicate stimulatory and inhibitory effects, respectively.

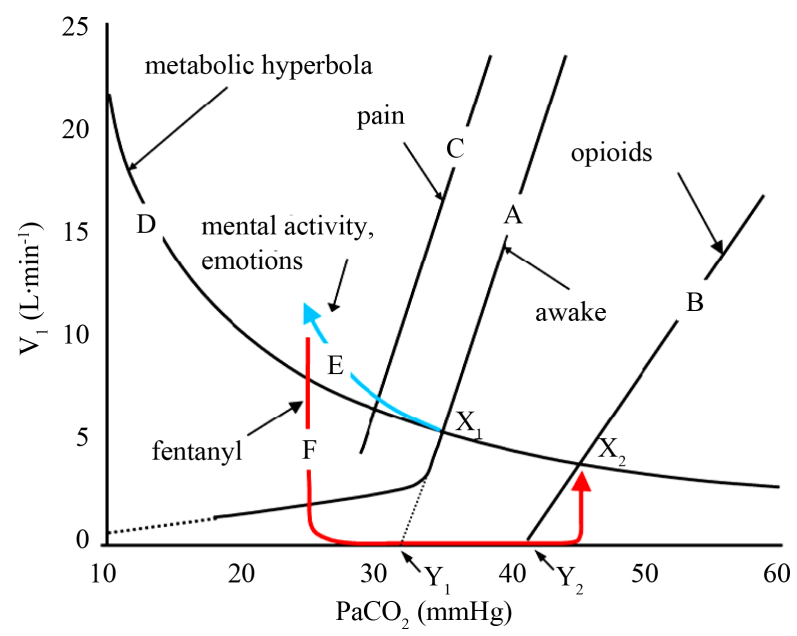

Figure 3. Effects of opioids, pain, and emotions on the hypercapnic ventilatory response (HCVR). $\mathrm{V}_{\mathrm{I}}$, inspiratory minute volume and $\mathrm{PaCO}_{2}$, arterial carbon dioxide tension, respectively. Lines A, B, and C indicate HCVR while awake, affected by opioids, or pain, respectively. The curve D indicates the metabolic hyperbola. Arrows $\mathrm{E}$ and $\mathrm{F}$ indicate ventilatory responses produced by emotional instability and a bolus dose of fentanyl. Points $\mathrm{X}_{1}$ and $\mathrm{X}_{2}$ indicate resting breathing levels while awake and during an administration of fentanyl. Points $Y_{1}$ and $Y_{2}$ are the apneic thresholds. 
The aforementioned mechanisms are only speculative, and we are unable to propose explicit mechanisms that produced apnea in the patient. We, therefore, may need to consider technical misconducts that could have precipitated the patient's breathing condition. Residual remifentanil still existing in the venous route could have caused apnea. It was, however, unlikely because the remifentanil infusion was terminated with the syringe unhitched more than 30 min before the apneic episode. Accidental retrograde infusion of remifentanil into the i.v. fluid bag would be another possibility. It is also negated since a one-way valve was in place between the syringe line and the i.v. fluid bag.

We might lack a thoughtful anesthesia management. First, the patient revealed apnea some 30 min after TAP blocks and at the emergence from anesthesia. Griffiths et al. [20] reported that $3 \mathrm{mg} \cdot \mathrm{kg}^{-1}$ of ropivacaine administered by TAP blocks in adult female patients resulted in potentially toxic plasma concentrations with the peak concentration occurring 30 min post-injection. Latzke et al. [21] demonstrated that a time to the maximum concentration of plasma ropivaine was $0.44 \pm 0.36 \mathrm{~h}$ (mean $\pm \mathrm{SD}$ ) after injection in 8 healthy volunteers administered 150 mg ropivacaine by TAP block. However, neither signs of neurotoxicity [22] nor cardiovascular instability were detected in our case. It indicates that the central effect of ropivacaine on the respiratory depression, even if it existed, would be negligible. Though, we might better administer TAP blocks preoperatively. Second, we administered bolus doses of fentanyl while applying a continuous infusion of remifentanil. We intended to use fentanyl for a smooth transition from remifentanil for anesthesia to postoperative IV-PCA fentanyl. However, a short duration of the surgery (62 min) made us to administer fentanyl in the midst of remifentanil infusion. Third, high preoperative anxiety was shown to be negatively associated with recovery from anesthesia and control of postoperative pain [23]. A use of anxiolytics in addition to analgesics might be an appropriate choice at the emergence from anesthesia since the patient could be expected to be susceptible to postoperative agitation, considering her fragile mentality [24]. Fourth, an insufflation of sevoflurane in an attempt to relieve ventilation difficulty might be inappropriate [25]. However, we were unable to immediately prepare intravenous glottis dilators such as a muscle relaxant and propofol when we faced with the ventilation difficulty.

\section{Conclusion}

In the immediate postoperative period, transient factors such as pain, mental instability, and anesthetic residues, which are indirectly related to breathing, can interact with each other and with opioid. Such interactions can induce apnea through mechanisms combined among direct inhibition of the respiratory center, and chemical and cortical controls of breathing. This report emphasizes the importance of comprehensive knowledge of the respiratory effect of opioids, and other factors that can affect chemical and cortical controls of breathing in the postoperative pain management.

\section{References}

[1] Shapiro, A., Zohar, E., Zaslansky, R., Hoppenstein, D., Shabat, S. and Fredman, B. (2005) The Frequency and Timing of Respiratory Depression in 1524 Postoperative Patients Treated with Systemic or Neuraxial Morphine. Journal of Clinical Anesthesia, 17, 537-542. http://dx.doi.org/10.1016/j.jclinane.2005.01.006

[2] Overdyk, F.J., Carter, R., Maddox, R.R., Callura, J., Herrin, A.E. and Henriquez, C. (2007) Continuous Oximetry/Capnometry Monitoring Reveals Frequent Desaturation and Bradypnea during Patient-Controlled Analgesia. Anesthesia and Analgesia, 105, 412-418. http://dx.doi.org/10.1213/01.ane.0000269489.26048.63

[3] Dick, T.E., Orem, J.M. and Shea, S.A. (1997) Behavioral Control of Breathing. In: Crystal, R.G., West, J.B., Barnes, P.J. and Weibel, E.R., Eds. The Lung: Scientific Foundations, 2nd Edition, Lippincott-Raven Publishers, Philadelphia, 1821-1837.

[4] Walsh, T.D. (1984) Oral Morphine in Chronic Cancer Pain. Pain, 18, 1-11. http://dx.doi.org/10.1016/0304-3959(84)90121-0

[5] Arita, H., Kogo, N. and Ichikawa, K. (1988) Locations of Medullary Neurons with Non-Phasic Discharges Excited by Stimulation of Central and/or Peripheral Chemoreceptors and by Activation of Nociceptors in Cat. Brain Research, 442, 1-10. http://dx.doi.org/10.1016/0006-8993(88)91426-6

[6] Borgbjerg, M.F., Nielsen, K. and Franks, J. (1996) Experimental Pain Stimulates Respiration and Attenuates Morphine-Induced Respiratory Depression: A Controlled Study in Human Volunteers. Pain, 64, 123-128. http://dx.doi.org/10.1016/0304-3959(95)00088-7

[7] Keefe, F.J., Lumley, M., Anderson, T., Lynch, T. and Carson, K.L. (2001) Pain and Emotion: New Research Direc- 
tions. Journal of Clinical Psychology, 57, 587-607. http://dx.doi.org/10.1002/jclp.1030

[8] Fink, B.R., Hanks, E.C., Ngai, S.H. and Papper, E.M. (1963) Central Regulation of Respiration during Anesthesia and Wakefulness. Annals of the New York Academy of Sciences, 109, 892-900. http://dx.doi.org/10.1111/j.1749-6632.1963.tb13514.x

[9] Combes, X., Cerf, C., Bouleau, D., Duvaldestin, P. and Dhonneur, G. (2000) The Effects of Residual Pain on Oxygenation and Breathing Pattern during Morphine Analgesia. Anesthesia and Analgesia, 90, 156-160. http://dx.doi.org/10.1097/00000539-200001000-00033

[10] Alsahaf, M.H. and Martin, S. (2000) Respiratory Failure Due to the Combined Effects of Transdermal Fentanyl and Epidural Bupivacaine/Diamorphine following Radical Nephrectomy. Journal of Pain and Symptom Management, 20, 210-213. http://dx.doi.org/10.1016/S0885-3924(00)00173-1

[11] Hanks, G.W., Twycross, R.G. and Lloyd, J.W. (1981) Unexpected Complication of Successful Nerve Block. Anaesthesia, 36, 37-39. http://dx.doi.org/10.1111/j.1365-2044.1981.tb08596.x

[12] Wells, C.J., Lipton, S. and Lahuerta, J. (1984) Respiratory Depression after Percutaneous Cervical Anterolateral Cordotomy in Patients on Slow-Release Oral Morphine. Lancet, 1, 739. http://dx.doi.org/10.1016/S0140-6736(84)92251-7

[13] Gilbert, C. (2003) Clinical Applications of Breathing Regulation: Beyond Anxiety Management. Behavior Modification, 27, 692-709. http://dx.doi.org/10.1177/0145445503256322

[14] Sarton, E., Dahan, A., Teppema, L., Berkenbosch, A., van den Elsen, M. and van Kleef, J. (1997) Influence of Acute Pain Induced by Activation of Cutaneous Nociceptors on Ventilatory Control. Anesthesiology, 87, 289-296. http://dx.doi.org/10.1097/00000542-199708000-00016

[15] Pattinson, K.T.S. (2008) Opioids and the Control of Respiration. British Journal of Anaesthesia, 100, 747-758. http://dx.doi.org/10.1093/bja/aen094

[16] Abrams, J.T., Horrow, J.C., Bennett, J.A., Van Riper, D.F. and Storella, R.J. (1996) Upper Airway Closure: A Primary Source of Difficult Ventilation with Sufentanil Induction of Anesthesia. Anesthesia and Analgesia, 83, 629-632. http://dx.doi.org/10.1097/00000539-199609000-00034

[17] Bennett, J.A., Abrams, J.T., Van Riper, D.F. and Horrow, J.C. (1997) Difficult or Impossible Ventilation after Sufentanil-Induced Anesthesia Is Caused Primarily by Vocal Cord Closure. Anesthesiology, 87, 1070-1074. http://dx.doi.org/10.1097/00000542-199711000-00010

[18] Scamman, F.L. (1983) Fentanyl O2 N2O Rigidity and Pulmonary Compliance. Anesthesia and Analgesia, 62, 332-334. http://dx.doi.org/10.1213/00000539-198303000-00008

[19] Lalley, P.M. (2003) $\mu$-Opioid Receptor Agonist Effects on Medullary Respiratory Neurons in the Cat: Evidence for Involvement in Certain Types of Ventilatory Disturbances. American Journal of Physiology. Regulatory Integrative and Comparative Physiology, 285, R1287-R1304.

[20] Griffiths, J.D., Barron, F.A., Grant, S., Bjorksten, A.R., Hebbard, P. and Royse, C.F. (2010) Plasma Ropivacaine Concentrations after Ultrasound-Guided Transversus Abdominis Plane Block. British Journal of Anaesthesia, 105, 853-856. http://dx.doi.org/10.1093/bja/aeq255

[21] Latzke, D., Marhofer, P., Kettner, S.C., Koppatz, K., Turnheim, K., Lackner, E., Sauermann, R., Müller, M. and Zeitlinger, M. (2012) Pharmacokinetics of the Local Anesthetic Ropivacaine after Transversus Abdominis Plane Block in Healthy Volunteers. European Journal of Clinical Pharmacology, 68, 419-425. http://dx.doi.org/10.1007/s00228-011-1139-8

[22] Knudsen, K., Beckman Suurküla, M., Blomberg, S., Sjövall, J. and Edvardsson, N. (1997) Central Nervous and Cardiovascular Effects of I.V. Infusions of Ropivacaine, Bupivacaine and Placebo in Volunteers. British Journal of Anaesthesia, 78, 507-514. http://dx.doi.org/10.1093/bja/78.5.507

[23] Ali, A., Altun, D., Oguz, B.H., Ilhan, M., Demircan, F. and Koltka, K. (2014) The Effect of Preoperative Anxiety on Postoperative Analgesia and Anesthesia Recovery in Patients Undergoing Laparascopic Cholecystectomy. Journal of Anesthesia, 28, 222-227. http://dx.doi.org/10.1007/s00540-013-1712-7

[24] Sanders, R.D., Pandharipande, P.P., Davidson, A.J., Ma, D. and Maze, M. (2011) Anticipating and Managing Postoperative Delirium and Cognitive Decline in Adults. BMJ 343, d4331. http://dx.doi.org/10.1136/bmj.d4331

[25] Visvanathan, T., Kluger, M.T., Webb, R.K. and Westhorpe R.N. (2005) Crisis Management during Anaesthesia: Laryngospasm. Quality \& Safety in Health Care, 14, e3. http://dx.doi.org/10.1136/qshc.2002.004275 
Scientific Research Publishing (SCIRP) is one of the largest Open Access journal publishers. It is currently publishing more than 200 open access, online, peer-reviewed journals covering a wide range of academic disciplines. SCIRP serves the worldwide academic communities and contributes to the progress and application of science with its publication.

Other selected journals from SCIRP are listed as below. Submit your manuscript to us via either submit@scirp.org or Online Submission Portal.
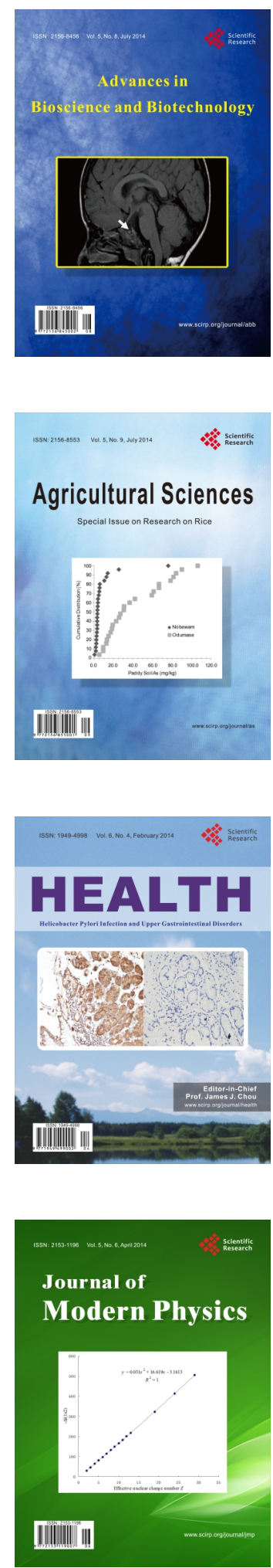
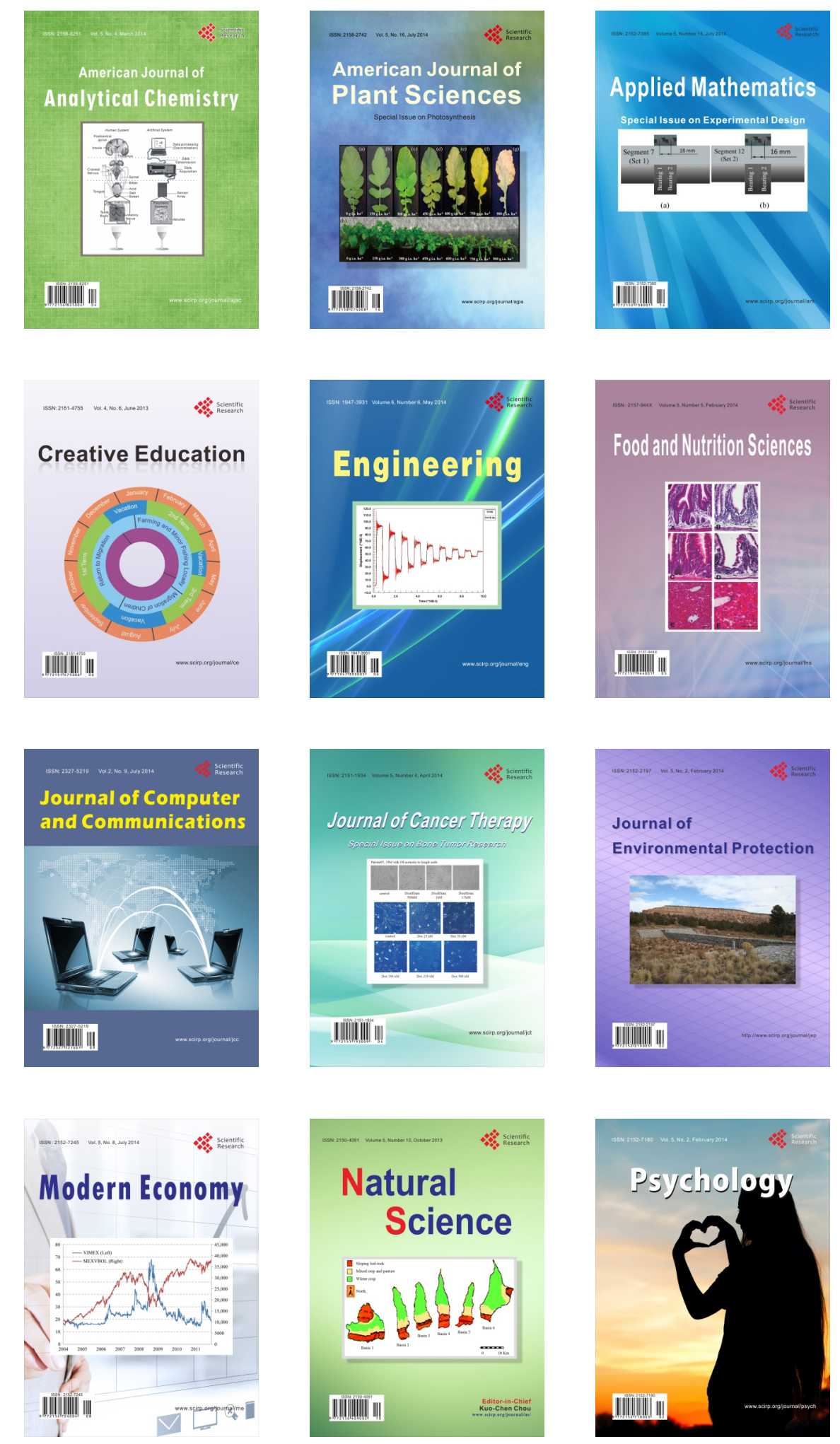